\title{
Quality Assessment of Topographic Data Automatic Map Generalization from Scale 1:10 000 to 1:50 000
}

\author{
LUO Fujun ${ }^{\mathrm{a}}$, ZHAO Yousong ${ }^{\mathrm{a},}{ }^{*}$, MA Xu ${ }^{\mathrm{a}}, \mathrm{WU} \mathrm{Xuan}^{\mathrm{a}}$ \\ ${ }^{a}$ National Quality Inspection and Testing Center for Surveying and Mapping Products, LUO Fujun,1254020931@qq.com, ZHAO \\ Yousong,2310931713@qq.com,MAXu,52202002@qq.com,WUXuan,84924075@qq.com \\ * Corresponding author
}

Founded by National Natural Science Foundation of China ( NO. 41671440)

\begin{abstract}
Map generalization is not only affected by the factors such as map usage, scale, and feature distribution characteristics, but also affected by the level of understanding and skill of the mapper or computer. Under the same Constraint of indicator conditions, different mapper or computer use the same data but product different maps. Automatic map generalization is a kind of mapping technology with strong artificial intelligence, subjectivity and regionality. The necessary map comprehensive knowledge, experience of mapping and the correct comprehensive method of map are the key to the quality of the final map generalization product.

This paper takes the automatic map generalization test of topographic data in a certain area as an example, starting from the quality requirements of 1:50 000 scale topographic data, discussing the selection, simplification, combination, smoothing, enhancement, displacement, exaggeration, aggregation of geographical features. It puts forward the models, contents, indicators and methods for quality assessment, and analyzes the typical quality problems after the generalization of features such as water system, habitation, road, landform, vegetation, soil and annotation. This paper also discusses the shortcomings and optimization measures of current automatic generalization in strategy, knowledge base and so on. The work of this paper can provide technical support for perfecting the theory and method of automatic map generalization, provide scheme reference for the real and reasonable assessment of topographic data automatic map generalization, and provide practical reference for multi-scale topographic map linkage update.
\end{abstract}

Keywords: Automatic Generalization, Map Generalization, Linkage Update, Fast Mapping, Basic Surveying and Mapping

\section{Introduction}

1:50 000 topographic data is an indispensable basic and strategic information resource for land use and planning, resource survey and development, ecological monitoring and environmental protection, disaster prevention and mitigation, national defense construction. It is one of the most widely used and most frequently used basic mapping results. In order to better adapt to the urgent needs of highprecision, high-potential and rich-content basic geographic information resources for rapid economic development, and to provide a geospatial platform for the implementation of national information strategies, it is necessary to update the 1:50 000 terrain data in time.

The 1:50 000 terrain data update project is a technical information project with complex technology and arduous tasks. It involves a comprehensive application of a variety of new surveying and mapping technologies. The commonly used methods include comprehensive judgment, generalization update, and DRG digital update. Making full use of 1:10 000 terrain data for computer 
automatic map generalization is one of the efficient, practical technical methods for achieving rapid update of 1:50 000 terrain data. At present, numbers of softwares represented by WJ-III, Geoway, AutoMAP have appeared on the market, which has decomposed the generalization process and improved the efficiency of automatic generalization by using the human-computer interaction collaborative operation mode. The realization of the automatic map generalization of terrain data not only helps to liberate the traditional map compilation, which is time-consuming, labor-intensive. Its fast and accurate plotting features can play a role in emergency engineering, and can also support multi-level linkage update and solve more current problems. The integration of the scales to build the database, to meet the needs of the multiintegration base map, to support the country's "multiregulation" major strategy, is to subvert the traditional scale concept, update the elements according to the elements, and thus affect the upstream data acquisition and Handle the norms and promote the establishment of a new information-based surveying and mapping system. The generalization of terrain data is a scientific and creative process. It should be rationalized and scientifically processed according to the content of the map, the shape of the map, the number of features and the quality characteristics, so as to reflect the various information contained in the map as comprehensively as possible. With the development of automatic generalization of terrain data, the data quality problems caused by generalization can not be ignored. The lack of automatic generalization evaluation mechanism, the automatic generalization is more random; the lack of models and methods for the overall evaluation of generalization results, users can not obtain the overall quality of the overall situation.

At present, the analysis and evaluation of the problem of automatic generalization of terrain data is scattered and incomplete. Therefore, there are many issues that need to be studied and solved for the comprehensive evaluation of the automatic generalization algorithm, the quality control of the automatic generalization process and the results. This paper discusses the quality evaluation of the automatic generalization results by taking the quality test of 1:10 000 automatic drawdown 1:50 000 terrain data from a province in China using WJ-III as an example.

\section{Introduction of WJ-III}

The WJ-III map workstation is an automatic generalization software for terrain data developed by the China Academy of Surveying and Mapping. The software creates a cross-platform symbol library and an automatic synthesis and automatic charting knowledge engine. Through the integrated knowledge base and the mapping knowledge base, it can automate the integration and mapping of point and line, surface and other artificial and natural features. And the coordination of the relationship between the elements to achieve multi-level scale step by step or cross-scale automatic generalization, the degree of automation is as high as $95 \%$.

\section{Inspection Method}

Automatic generalization terrain data quality check commonly used programs are three kinds of technical methods and means such as automatic check, humancomputer interaction check, and manual check check. Different inspection methods have their own advantages, and usually need to be combined. When checking, you need to choose the appropriate method according to different elements or contents.

a) The program is automatically checked. Using computer graphics and attributes, graphics and graphics, certain logical relationships and rules between attributes and attributes, computer programs are programmed to perform automatic computer inspections of compliance check items.

b) Human-computer interaction check. Many places in the data cannot be completely determined by program check, but the program check can search for the suspected place, narrow the scope or precise positioning, and then use the human-computer interaction check method to judge the correctness of the data manually.

c) Manual control examination. The correctness of the content of the generalization results is checked by manually superimposing the reference data.

\section{Evaluation Content}

This paper deeply studies and analyzes 1:50 000 topographic data generalization production technical regulations, process flow, data usage requirements, data quality requirements, etc., based on value prioritization, retention nature, prominent differences, scale consistency, 
avoidance of ambiguity, etc. The research determines the content and indicators of the quality evaluation of automatic generalization, and evaluates the quality of terrain data from the aspects of positional accuracy, attribute accuracy, integrity, logical consistency and representation quality (Tab. 1).

\begin{tabular}{|c|c|c|c|c|c|}
\hline NO. & Quality Element & $\begin{array}{l}\text { Quality Sub- } \\
\text { element }\end{array}$ & Check Content & Check Result & Indicators \\
\hline \multirow{5}{*}{1} & \multirow{5}{*}{$\begin{array}{l}\text { Position } \\
\text { Accuracy }\end{array}$} & \multirow{3}{*}{$\begin{array}{l}\text { Horizontal } \\
\text { Accuracy }\end{array}$} & Control Point & \multirow{4}{*}{$\begin{array}{l}\qquad \mathrm{r}=\mathrm{n} / \mathrm{N} \times 100 \% \\
(\mathrm{r} \text { - Error Rate, } \mathrm{n} \text { - Total Number } \\
\text { of Errors, } \mathrm{N} \text { - Total Number of } \\
\text { full map features, The Same } \\
\text { Below) }\end{array}$} & \multirow{4}{*}{$r_{0}=0.3 \%$} \\
\hline & & & Match Accuracy & & \\
\hline & & & Displacement & & \\
\hline & & \multirow{2}{*}{$\begin{array}{l}\text { Height } \\
\text { Accuracy }\end{array}$} & Control Point & & \\
\hline & & & Contour Interval & Compatible/ Non-compatible & $\begin{array}{c}\text { Performed by } \\
\text { Technical Design }\end{array}$ \\
\hline \multirow{2}{*}{2} & \multirow{2}{*}{$\begin{array}{l}\text { Attribute } \\
\text { Accuracy }\end{array}$} & $\begin{array}{l}\text { Classification } \\
\text { Correctness }\end{array}$ & $\begin{array}{l}\text { Classification } \\
\text { Code Value }\end{array}$ & \multirow{2}{*}{$\mathrm{r}=\mathrm{n} / \mathrm{N} \times 100 \%$} & \multirow{2}{*}{$\mathrm{r}_{0}=0.3 \%$} \\
\hline & & $\begin{array}{c}\text { Attribute } \\
\text { Correctness }\end{array}$ & Attribute Value & & \\
\hline \multirow[t]{2}{*}{3} & \multirow[t]{2}{*}{ Integrity } & Redundant & $\begin{array}{c}\text { Redundant } \\
\text { Features }\end{array}$ & \multirow[t]{2}{*}{$\mathrm{r}=\mathrm{n} / \mathrm{N} \times 100 \%$} & \multirow[t]{2}{*}{$\mathrm{r}_{0}=0.3 \%$} \\
\hline & & Omission & Omission Features & & \\
\hline \multirow{11}{*}{4} & \multirow{11}{*}{$\begin{array}{c}\text { Logical } \\
\text { Consistency }\end{array}$} & \multirow[b]{2}{*}{$\begin{array}{l}\text { Conceptual } \\
\text { Consistency }\end{array}$} & Attribute Field & \multirow{5}{*}{ Compatible/ Non-compatible } & \multirow{5}{*}{$\begin{array}{c}\text { Performed by } \\
\text { Technical Design }\end{array}$} \\
\hline & & & $\begin{array}{c}\text { Data } \\
\text { Organization }\end{array}$ & & \\
\hline & & \multirow{3}{*}{$\begin{array}{c}\text { Format } \\
\text { Consistency }\end{array}$} & Data Archiving & & \\
\hline & & & Data Format & & \\
\hline & & & Data Naming & & \\
\hline & & \multirow{6}{*}{$\begin{array}{l}\text { Topological } \\
\text { Consistency }\end{array}$} & Coincide & \multirow{6}{*}{$\mathrm{r}=\mathrm{n} / \mathrm{N} \times 100 \%$} & \multirow{6}{*}{$\mathrm{r}_{0}=0.3 \%$} \\
\hline & & & Repeat & & \\
\hline & & & Break & & \\
\hline & & & Continuous & & \\
\hline & & & Closure & & \\
\hline & & & Interrupt & & \\
\hline \multirow{6}{*}{5} & \multirow{6}{*}{ Characterization } & \multirow{2}{*}{$\begin{array}{l}\text { Geometric } \\
\text { Expression }\end{array}$} & Geometric Type & \multirow{6}{*}{$\mathrm{r}=\mathrm{n} / \mathrm{N} \times 100 \%$} & \multirow{6}{*}{$\mathrm{r}_{0}=0.3 \%$} \\
\hline & & & $\begin{array}{l}\text { Geometric } \\
\text { Anomaly }\end{array}$ & & \\
\hline & & \multirow{4}{*}{$\begin{array}{l}\text { Geographical } \\
\text { Expression }\end{array}$} & $\begin{array}{c}\text { Feature } \\
\text { Selection } \\
\end{array}$ & & \\
\hline & & & $\begin{array}{l}\text { Graphical } \\
\text { Summary } \\
\end{array}$ & & \\
\hline & & & $\begin{array}{c}\text { Feature } \\
\text { Relationship }\end{array}$ & & \\
\hline & & & Directional Feature & & \\
\hline
\end{tabular}

Table 1. Evaluation content and indicators 


\section{Quality Problems}

\subsection{Water System}

The drawdown of water system elements should reflect the characteristics of the main water system in the region, the primary and secondary relationships, the distribution characteristics, and the overview of the water system ancillary facilities. The water network density should be fully considered in the comprehensive selection, the connectivity of each water system network should be maintained, and the basic position should be ensured. The shape cannot be changed greatly. Rivers distributed in a network should be represented, and small bends of linear rivers should be discarded (Stern et al, 2014); when different rivers meet or meet, ensure that the main rivers flow through; in order to avoid unreasonable line-crossing in the same river In the process of generalization, the geometry of the river (line, surface) should not be determined according to the width standard. Instead, the river should be unified according to the main part of the river.

After inspection, it was found that there were many quality problems in the WJ-III contracted water system, such as the discontinuity of the planar river (Fig. 1), and the redundant collection of river structure lines (Fig. 2). The river boundary was excessively unnatural and the flow was chaotic.

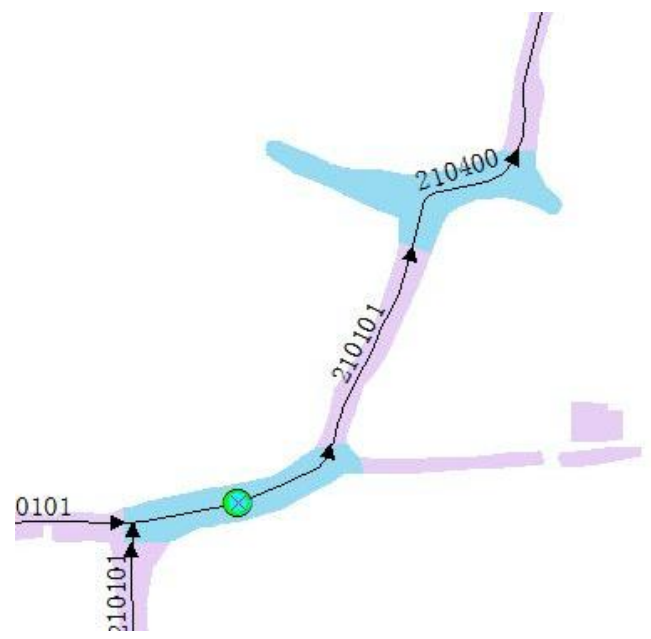

Figure 1. Loss of water features after generalization

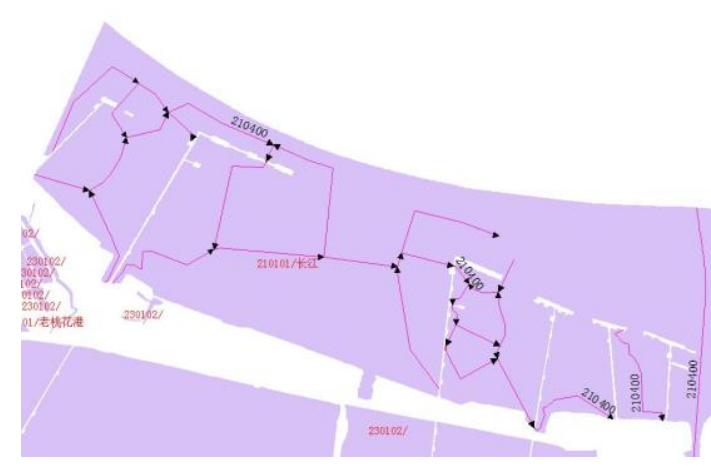

Figure 2. Excessive collection of river structure lines

\subsection{Habitation}

The drawdown of the residential area should maintain the density comparison of the habitation, reflecting the contour shape, distribution characteristics, connectivity, and the relationship with other elements of the habitation. It can reflect the density comparison of the residents in different areas, reflecting the difference in the density of the habitation along the map. The scale of the map scale is reduced and reduced.

After superimposing 1:10 000 data, it is found that there are many quality problems in the WJ-III generalization habitation, such as the missing contiguous blocks (Fig. 3). After the flat houses are generalizationed into point houses, the center is not at the geometric center (Fig. 4). After the integration of habitation, the internal gaps and loss distribution characteristics (Fig. 5) are not processed, and the generalization scale is inconsistent and the external contour features are lost (Fig. 6).

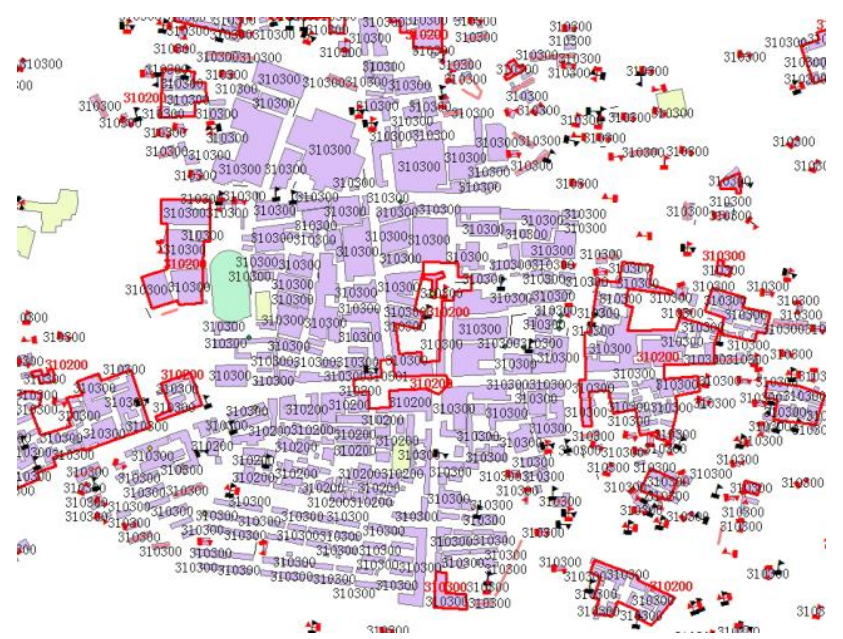

Figure 3. Missing contiguous block after generalization 


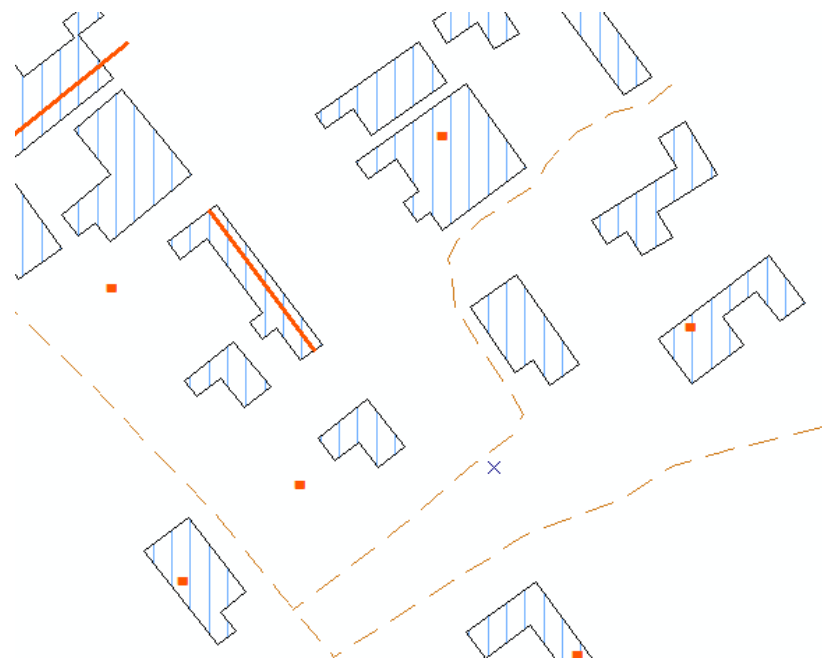

Figure 4. The center is not at the geometric center

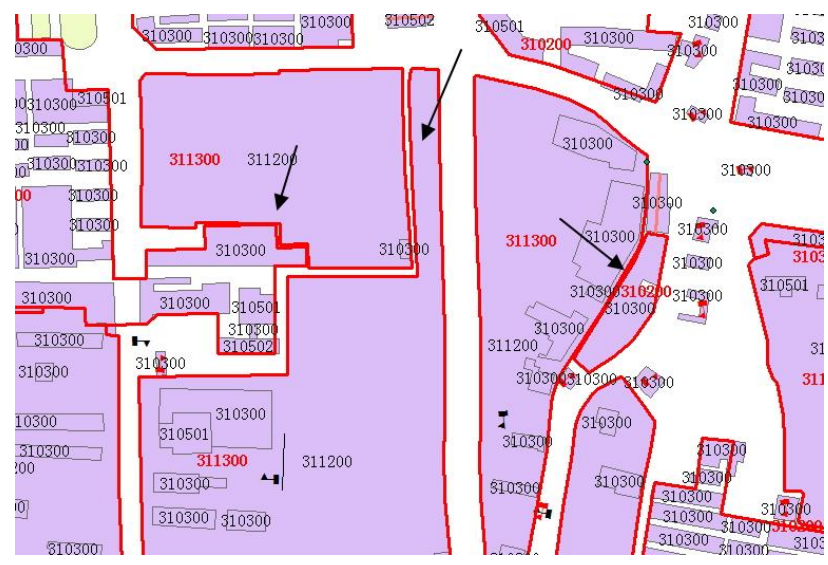

Figure 5. Internal gaps have not been processed of habitation

\subsection{Road}

The generalization of road elements should consider the factors such as the grade, length, density and connectivity of the road, and maintain the main characteristics of the selected road network in terms of geometry, semantics and topology (Topfer et al. 1966), which truly reflects the actual road conditions, railways and Level roads must be said to ensure that the road network inside the city is correctly displayed.

After inspection, it was found that WJ-III generalization road has many quality problems, such as the road network is not connected, the auxiliary facilities such as bridges are not abandoned after the road is deleted (Figure 6), the road connection relationship is handled incorrectly, and the road bridge is not collected in the road center. On the line, the urban road load is too large, and the attribute value is chosen after the road is merged.

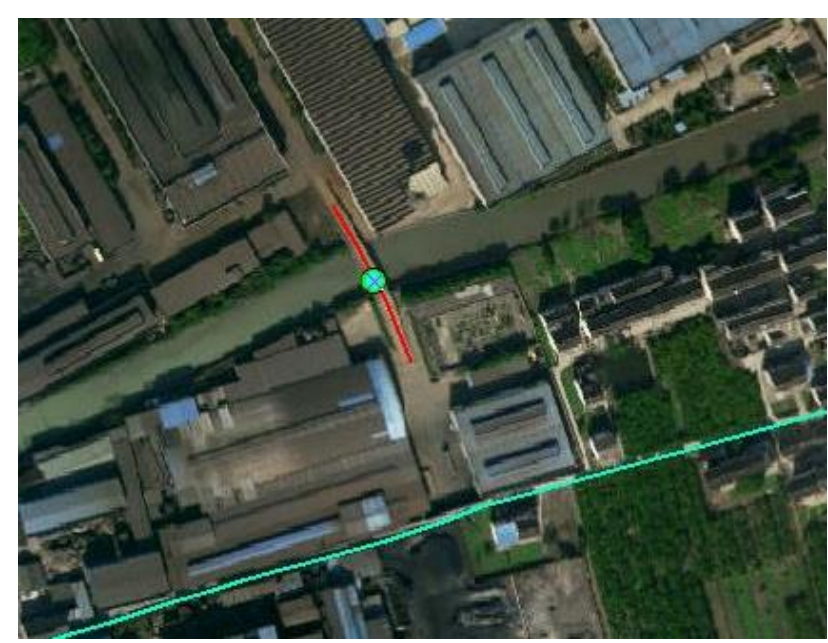

Figure 6. Abandoned ancillary facilities (bridges)

\subsection{Landform}

The generalization of geomorphic elements should be based on regional topographical features and the geomorphology should be expressed according to the specified contour height. The mountainous areas should correctly represent the morphological characteristics of ridges, hills, valleys, slopes and saddles according to the characteristics of different landform types, and properly handle and other features. The relationship of the elements. The contour should be smooth to avoid discounting or flutter; the contour should be a continuous curve and the intermittent contours should be connected.

After inspection, it was found that the main quality problem after the WJ-III generalization was that the contour lines were discontinuous (Fig. 7).

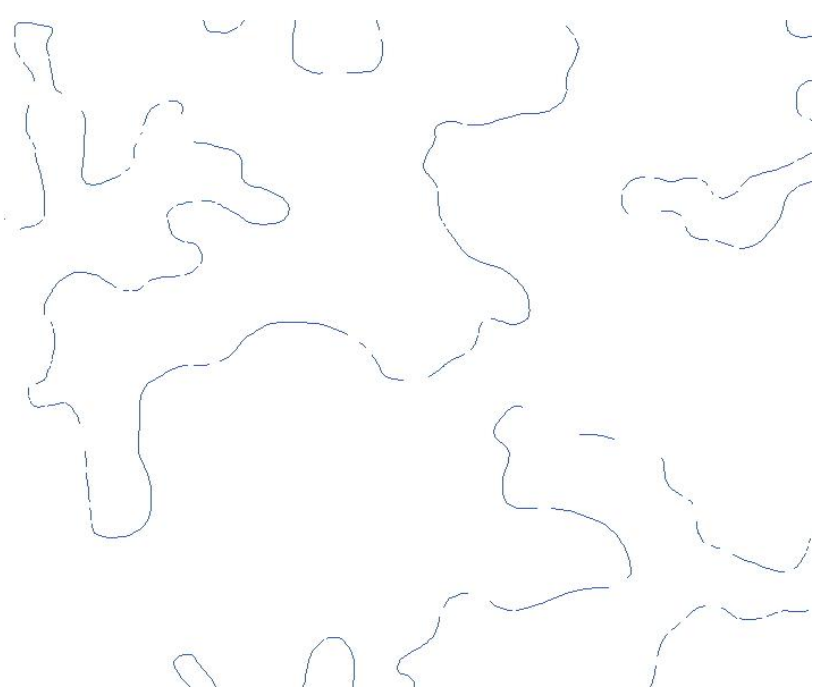

Figure 7. Contour line is not continuous after generalization

\section{Conclusion}

The WJ-III map workstation represents the highest level 
of research on automatic generalization of terrain data in China, but there are still a lot of quality problems in the generalization results, and there is still a long way to go from the quality requirements of 1:50000 terrain data. The current computer automatic generalization is still immature. To obtain the available generalization results, while optimizing algorithms, rules, rules, simplification, merging, smoothing, exaggeration, shifting, thinning, etc., it is still inseparable from the experience of generalization and A large number of manual interventions and late repairs by skill personnel.

\section{References}

Stern, Boris (2014). "Generalisation of Map Data". Geographic Information Technology Training Alliance: 08-11.

Topfer, F; Pillwizer, W (1966). "The Principles of Selection". The Cartographic Journal: 10-16. 